\title{
Cooperative Group Program
}

National Cancer Institute

\section{Source}

National Cancer Institute. Cooperative Group Program. NCI Thesaurus. Code C16008.

$\mathrm{NCl}$-sponsored program that promotes and supports clinical trials in cancer treatment, (larg ely combined modality approaches); cancer prevention, and early detection within setting of a Cooperative Group. 